\title{
Formação pedagógica na pós-graduação em saúde no ambiente Moodle: um compromisso social
}

\author{
Lidia Ruiz Moreno ${ }^{*}$, Maria Cecilia Sonzogno ${ }^{* *}$
}

\begin{abstract}
Resumo: Temos como objetivos refletir sobre o processo de formação docente e analisar as concepções e as práticas sobre aspectos didático-pedagógicos de pós-graduandos participantes da disciplina "Formação Didático-Pedagógica em Saúde" (FDPS), formato bimodal. Para a coleta de dados, utilizamos os questionários e as produçōes postadas em fóruns de discussão no Moodle. A análise dos dados atendeu os seguintes eixos: concepçōes e práticas sobre currículo, modelo biopsicossocial, formação docente, ensino-aprendizagem e avaliação. Os resultados mostraram predomínio de relatos sobre o modelo curricular tradicional nos cursos de graduação vivenciado(s) pelos pós-graduandos, embora seja possível identificar avanços relacionados à diversidade de práticas e de cenários de aprendizagem. As concepções e as práticas refletem o momento de transição do Ensino Superior brasileiro, no qual convivem abordagens baseadas no modelo biomédico, com mudanças ainda incipientes, sobre as quais é preciso refletir de forma crítica durante a formação docente em saúde.
\end{abstract}

Palavras-chave: ensino superior; tecnologia educacional; fórum de discussão; docência.

\section{The teaching practice in health post-graduate programs using the Moodle platform: a social commitment}

\begin{abstract}
The objectives of our study are to reflect on the academic education process and analyze the concepts and practices regarding didactic-pedagogical aspects of post-graduate students attending the 'Bimodal Didactic-Pedagogical Education in Health' discipline. Questionnaires and messages posted on discussion forums in the Moodle platform were used for data collection. The data analysis was based on the following areas: curriculum conceptions and practices, biopsychosocial model, teachers' education, teaching-learning and evaluation. Our results revealed that there is a predominance of reports concerning the traditional curriculum model in undergraduate courses experienced by the post-graduate students, although it was possible to identify some progress related to the diversity of practices and learning settings. The concepts and practices reflect the transition faced by the Brazilian Higher Education nowadays, where approaches based on the biomedical

Professora do Programa de Mestrado "Ensino em Ciências da Saúde", do Centro de Desenvolvimento do Ensino Superior em Saúde da Universidade Federal de São Paulo (Cedess/ Unifesp),Brasil. lidia.ruiz@unifesp.br

** Professora do Programa de Mestrado "Ensino em Ciências da Saúde" e Diretora do Cedess/ Unifesp, SP, Brasil. mcsonzogno@unifesp.br
\end{abstract}


model coexist with very subtle changes, on which we must reflect critically during teaching education in Health.

Key words: higher education; educational technology; discussion forum; teaching.

\section{Introdução}

O Centro de Desenvolvimento do Ensino Superior em Saúde - Cedess é um órgão complementar da Universidade Federal de São Paulo - Unifesp que congrega atividades de ensino, pesquisa e extensão. A Unifesp, em princípio, uma universidade da área da saúde, a partir de 2006 vem implantando um processo de expansão, com a abertura de novos cursos e campi, configurando uma efetiva universalização do saber (Seiffert, 2006).

Dentre as atividades desenvolvidas no Cedess, a disciplina "Formação Didática Pedagógica em Saúde” (FDPS), oferecida desde 1996 a todos os pós-graduandos da Unifesp, que compóem um universo de aproximadamente três mil alunos, constitui um cenário de docência e pesquisa privilegiado pelo corpo docente, integrado por profissionais de diferentes áreas de conhecimento: Humanas, Sociais, Biológicas e Saúde (Batista, 2004; Cedess, 2006).

A discussão sobre formação docente no Brasil é recente, tendo seu marco na década de 1990 - no movimento de profissionalização do ensino. Em seu início, a atuação docente enfatizava o conhecimento específico de uma determinada área, bem como o sucesso na atuação profissional (Nunes, 2001). No atual cenário, novas demandas surgem no sentido de aproximar o processo de formação profissional às necessidades da população, considerando a complexidade dos problemas que a realidade apresenta. Com a finalidade de adequar a formação docente à conjuntura sociopolítica brasileira, consideramos prioritário articular o processo de formação didático-pedagógica em saúde às atuais políticas de Educação e Saúde vigentes no País.

Nesse cenário de mudanças nas políticas de saúde, especificamente as acontecidas a partir do movimento da Reforma Sanitária, que deu origem à implantação do Sistema Único de Saúde (SUS), profundas readequações estão sendo realizadas nas Instituiçóes de Ensino Superior (IES). As Diretrizes Curriculares Nacionais para os cursos da saúde (Brasil, 2000-2002) constituem um importante marco na formação dos profissionais da área da saúde e nos processos de formação docente.

A importância de refletir sobre a realidade do sistema educacional brasileiro justifica-se pelo fato de que os docentes geralmente tendem a reproduzir modelos que vivenciaram como alunos e apresentam dificuldade para incorporar novos procedimentos e recursos de ensino (Masetto, 2003). 
Salientamos ainda que a pós-graduação no Brasil tem dois grandes objetivos: a formação do pesquisador, atendendo à demanda de produção de conhecimento; e a formação docente, atuando como multiplicador em suas ações de docência-pesquisa e extensão. Essas ações constituem-se como fundamentais e devem ser exercidas pelos docentes na consolidação das mudanças nas IES e na sua articulação com os serviços de saúde (Freitas; Seiffert, 2007). A valorização do processo de formação docente na Unifesp traduz-se na implantação do Programa de Aperfeiçoamento Docente (PAD) junto aos pós-graduandos bolsistas da Coordenadoria de Aperfeiçoamento de Pessoal de Nível Superior-Capes, que, após terem cumprido os créditos na disciplina FDPS, exercem a função de auxiliares docentes em cursos de graduação, orientados pelos professores responsáveis pelos componentes curriculares.

A FDPS tem como objetivo preparar o pós-graduando para o exercício da docência em saúde, buscando não apenas uma perspectiva técnica, mas ampliando sua visão crítica da prática docente. Os núcleos temáticos privilegiados abordam: políticas públicas para a educação superior brasileira; modelo biopsicossocial; currículo; planejamento educacional em saúde; processo de ensino-aprendizagem na perspectiva das principais tendências pedagógicas; metodologias ativas; comunicação e avaliação do processo ensino-aprendizagem. A elaboração de um planejamento educacional, desenvolvido em pequenos grupos durante a disciplina, visa articular os conceitos construídos com situaçóes do cotidiano dos participantes (Batista et al., 2004).

As ideias de Vygotsky (1896-1934) e de Paulo Freire (1921-1997), embora partindo de perspectivas teóricas distintas, constituíram os fundamentos para estabelecer e consolidar nossa proposta de formação docente. Vygotsky (1998) construiu sua teoria tendo por base o desenvolvimento do indivíduo num contexto sócio-histórico, enfatizando o papel da cultura, ou seja, da esfera social. O autor tem como questão central a construção de conhecimentos pela interação do sujeito com o meio. Paulo Freire, assumindo como referência a "humanização do ser", compartilha a ideia de que "o homem não pode ser compreendido fora de suas relações com o mundo, de vez que é um ser situado, um ser do trabalho e da transformação do mundo" (Freire, 1979, p. 28).

O propósito da disciplina de FDPS é oportunizar a vivência de distintos momentos de formação, articulando reflexões e debates sobre a educação superior brasileira e a docência na área da saúde, utilizando uma variedade de recursos e Tecnologias de Informação e Comunicação (TIC) no âmbito do processo de ensino-aprendizagem. Este propósito levou-nos a estruturar, em 2007, uma proposta educativa bimodal que compreende quatro encontros presenciais e cinco a distância, desenvolvidos no ambiente virtual de aprendizagem Moodle (RuizMoreno et al., 2010). 
Durante os encontros presenciais e virtuais são desenvolvidos mapas conceituais, preleções dialogadas, dinâmicas de grupo, relatos de experiências, desenhos, cartas, fóruns de discussão e diversas ferramentas disponíveis no Moodle. Essa dinâmica bimodal tem efetivamente mobilizado o resgate de saberes dos estudantes, conduzindo-os à (re)construção coletiva de conhecimentos (Ruiz-Moreno et al., 2008). Ryan e Scott (2008) referem a relevância do uso dessas tecnologias na formação inicial de professores reflexivos e críticos.

O planejamento educacional, realizado em pequenos grupos, tanto em momentos presenciais como a distância, constitui um processo de construção coletiva que projeta uma proposta de trabalho pedagógico, tomando como referência contextos da educação e da saúde. Esse processo "envolve a explicitação das intencionalidades, favorecendo não apenas aprendizagens ao ato de planejar, mas uma reflexão sobre os compromissos sociais do docente na área da saúde” (Batista, 2004, p. 209).

\section{Objetivos da pesquisa e procedimentos metodológicos}

No presente estudo, temos como objetivos refletir sobre o processo de formação docente e analisar as concepções e as práticas sobre aspectos didático-pedagógicos dos pós-graduandos participantes da disciplina de FDPS.

Para a coleta de dados, foram utilizados questionários, relatos, mensagens postadas em fóruns de discussão e participação no wiki (ferramenta do Moodle que permite a construção de textos de forma coletiva); também foram analisados os planejamentos educacionais elaborados em pequenos grupos. Os eixos orientadores para a análise dos dados foram: concepções e práticas sobre currículo, modelo biopsicossocial, formação docente, processo de ensino-aprendizagem e avaliação. Os participantes da pesquisa foram 90 pós-graduandos, integrantes de três turmas da Disciplina de FDPS, oferecidas em 2008 e 2009.

\section{Resultados e discussão}

Com o propósito de caracterizar e refletir sobre as experiências vivenciadas pelos pós-graduandos nos cursos da área da saúde, foram solicitados relatos de experiência sobre a proposta curricular dos cursos de graduação. Os alunos, oriundos de diferentes regiões do País, comentaram sobre os currículos dos cursos de Medicina, Enfermagem, Ciências Biológicas, Biomedicina, Farmácia e Bioquímica, Fisioterapia, Nutrição, Fonoaudiologia e Psicologia, oferecidos por instituições brasileiras de Ensino Superior públicas e privadas.

Esses relatos evidenciam especificidades segundo a área de formação, mas também semelhanças nos movimentos de mudança, nos diferentes cursos. Foi possível perceber consonância entre as inovaçôes acontecidas posteriormente à promulgação das Diretrizes Curriculares Nacionais. 
Contudo, a maioria dos estudantes vivenciou, durante a graduação, propostas curriculares tradicionais, pouco flexíveis, disciplinares, com conteúdos fragmentados e escassa oferta de disciplinas eletivas. A formação privilegiava aspectos técnicos, sendo secundarizada a formação humanista e os aspectos didático-pedagógicos. Os egressos do curso médico expressaram que os modelos curriculares anteriores às Diretrizes Curriculares mantinham a fragmentação disciplinar, apresentavam propostas rígidas, centradas no modelo hospitalocêntrico, com escassa inserção na comunidade, orientação precoce à especialidade e dicotomia básico-clínica:

O currículo da faculdade era formado por disciplinas. Minha formação girou em torno de um ciclo básico de formação teórica de quatro semestres seguidos de mais quatro semestres em sala de aula com algumas aulas práticas no Hospital Universitário e por fim o internato no sexto ano, no qual ficávamos somente no hospital. No meu ponto de vista havia pouca integração teórica e prática. (Médica)

A organização curricular fragmentada foi apontada como característica da maioria dos cursos de graduação realizados pelos participantes:

\begin{abstract}
Eu mesma sempre vi as minhas aulas ou disciplinas na faculdade como "caixas" fechadas. Os professores não estavam preocupados em interligar as informaçôes de uma disciplina com a outra, $e$ sim em dar o conteúdo que foi estipulado. Em minha opiniāo, o currículo atualmente ainda é baseado apenas nos conteúdos, e não em habilidades e competências. (Bióloga)
\end{abstract}

Os alunos procuravam realizar atividades não previstas no currículo formal para minimizar as lacunas nos cursos em que as propostas curriculares distavam da prática e da realidade do mundo do trabalho. No dizer de Maia (2004), as experiências não planejadas podem configurar um currículo paralelo, em que se situam as atividades que o aluno busca espontaneamente, no âmbito da própria instituição, como é o caso de estágios em serviços e laboratórios. Já o currículo informal consiste nas experiências de formação procuradas pelo estudante fora da instituição. "Contudo, muitas vezes as experiências que neles se desenvolvem não são transpostas para o currículo planejado por falta de desejo político ou por dificuldades materiais" (Maia, 2004, p. 11).

Os pós-graduandos egressos de curso de Medicina corroboraram o apontado pelo autor e destacaram, na formação recebida, deficiências para atuar no sistema de saúde:

Venho de uma época em que o ensino vinha de "cima para baixo" e minha grade curricular básica não tinha nenhuma 
ou muito pouca ligação entre as disciplinas. Ainda que alguns fizessem cursos e ligas alternativas, tipo Banco de Sangue, Liga de DST ou antigo SCDST, plantóes na maternidade... Quando me formei, em 1992, saí pensando em atender os convênios médicos e não o SUS. (Médico)

Os egressos que concluíram a graduação em períodos posteriores ao estabelecimento das Diretrizes Curriculares relataram que os cursos mantiveram o modelo curricular tradicional e que as mudanças, quando aconteceram, corresponderam à organização do currículo nuclear, ao desenvolvimento de projetos multiprofissionais e a enfoques problematizadores da realidade:

\begin{abstract}
Apesar de ter me formado em 2006, quando as Diretrizes Curriculares já haviam sido implantadas, a universidade (particular) onde estudei ainda adotava o curriculo tradicional. Algumas tentativas de interdisciplinaridade foram introduzidas nas disciplinas eletivas, que consistiam em cursos voltados às ciências sociais, humanas e às artes. Com relação à inserção ao SUS, não existiu tal preocupação, sendo nossa formação orientada essencialmente à prática profissional no serviço privado de saúde.

(Biomédica)

Os conteúdos mais especificos passaram a ser abordados de duas formas: aprendizado baseado em problemas e, principalmente, modelo baseado na apresentação clínica. (Fonoaudióloga)

$\mathrm{Na}$ minha universidade somente existia o currículo "antigo", com várias disciplinas que não possuíam muita ligação. Posteriormente, um novo modelo de currículo foi aplicado, chamado de Programas de Aprendizagem (PA). Em cada semestre existiam módulos, onde todas as disciplinas eram voltadas para o mesmo assunto. (Bióloga)
\end{abstract}

$\mathrm{Na}$ nossa proposta disciplinar, o fórum de discussão sobre o modelo biopsicossocial e o currículo foi disponibilizado durante uma semana no Moodle e, nesse período, foram postadas 120 mensagens por 87 alunos dos potenciais 90 participantes. A análise das mensagens evidenciou reflexões e questionamentos sobre os seguintes conceitos: pensamento cartesiano, ciência positivista, relatório Flexner, modelo biomédico, modelo biopsicossocial e concepção holística.

Propostas curriculares baseadas no modelo biomédico foram vivenciadas pela maioria dos participantes. Porém, a adoção de uma perspectiva interdisciplinar e a inserção em cenários comunitários evidenciou movimentos de mudanças, segundo os relatos dos participantes:

Percebo que os profissionais que vivenciaram mudanças curriculares, embora continuem voltados à especificidade da profissão,

Pro-Posiçóes, Campinas, v. 22, n. 3 (66), p. 149-164, set./dez. 2011 
tiveram maior inserção na comunidade mais carente, o que proporcionou uma visão mais abrangente dos problemas locais. $O$ aprendizado foi mais humanizado e integrador, facilitando a prática profissional. (Enfermeiro)

Formei-me em psicologia em 2001 e, quando penso no curriculo da minha faculdade, percebo que ele era muito direcionado para psicologia de consultório, de RH (Recursos Humanos) de empresas ou de escola infantil. No meu currículo, nem se falava em atendimento hospitalar, nem psicologia hospitalar; muito menos de inserção no SUS. Acredito que tudo tenha mudado bastante, pois hoje em dia a psicologia em hospitais e programa da familia-PSF tornaram-se áreas de grande interesse para os psicólogos. (Psicólogo)

A conformação multiprofissional das turmas da disciplina de FDPS permitiu que os pós-graduandos ampliassem sua compreensão sobre a realidade dos diferentes cursos da área da saúde e o processo de transformação, de acordo com a atual legislação.

No fórum de discussão sobre modelo biopsicossocial e currículo, foi possível identificar disparidade de concepções sobre a missão da universidade. Um grupo minoritário de alunos defendeu a importância de desenvolver competências voltadas exclusivamente para o mercado de trabalho. Esse entendimento sobre a função da universidade relacionada à preparação de profissionais liberais gerou uma fecunda discussão, na qual a maioria dos pós-graduandos se posicionou positivamente sobre a responsabilidade das IES em formar profissionais comprometidos com as necessidades do conjunto da sociedade, o que requer desenvolver competências não somente técnicas, mas também humanísticas. Na visão de Peres e colaboradores (2007), os egressos devem estar aptos para atuar no mundo do trabalho, em espaços públicos e privados, utilizando seu conhecimento para gerar mudanças no espaço social, o que demanda uma postura ético-política. Nesse sentido, como qualquer obra humana, o projeto político-pedagógico das IES não é neutro, mas baseado em diferentes visóes de mundo, de sociedade e de homem. A seguinte fala explicita este posicionamento:

Sou formada na Unifesp em fonoaudiologia há quase seis anos, e muita coisa mudou desde que me formei em 2003. Acredito muito no modelo biopsicossocial, pois faz com que o aluno se insira em sua sociedade e saib como aplicar o seu conhecimento no dia a dia. (Fonoaudióloga)

Ao indagar sobre a inserção dos profissionais da saúde no Sistema Único de Saúde (SUS), foi possível perceber, nas mensagens, que ainda persistem lacunas entre as propostas curriculares e a realidade do sistema de saúde do País, no qual a maioria da população (de baixo poder aquisitivo) é atendida. 
Mesmo com a existência das DCN, vemos que cada um tem uma história e uma vivência diferente na graduação. Ademais, somos de diversas áreas e de regióes bem distintas também. Fui aluno de universidade privada, que utilizava curriculo tradicional por disciplinas, pautado no modelo biomédico e tecnicista, mas, mesmo utilizando os recursos do SUS em seus campos de prática supervisionados, não preparavam o aluno para atuação junto ao SUS. (Médico)

Movimentos de mudança em relação à formação profissional para atuar no SUS foram evidenciados em diversas áreas:

Eu acredito que as Diretrizes Curriculares da área da saúde avançaram significativamente, ao definir que a formação dos profissionais seja baseada em competências que permitam ao profissional atuar com qualidade, principalmente no SUS. (Enfermeiro)

No curso de Fonoaudiologia, durante todo o percurso, aprendemos a ter uma visão holística do paciente, considerando não apenas a sintomatologia de determinada(s) patologia(s), mas todo o contexto no qual aquele está inserido. Sem dúvidas, o "dar-se conta de que o homem é um todo em si", permite a integração e inter-relação de inúmeros conhecimentos, entre várias áreas e, consequentemente, uma atuação mais eficaz $e$ efetiva, seja em relação a prevenção, diagnóstico ou tratamento. (Fonoaudióloga)

A participação no fórum de discussão sobre currículo propiciou a consulta da bibliografia sugerida e a construção de conhecimentos sobre os modelos que inspiraram a elaboração dos currículos. Foi consensual entre os pós-graduandos a importância de os currículos de graduação desenvolverem práticas de saúde de orientação holística, com compromisso social e incorporarem o modelo da integralidade e humanização da assistência, bem como promoverem competências de educação permanente.

No Módulo Ensino-Aprendizagem foi proposto inicialmente que os estudantes colocassem no wiki suas concepçôes sobre ensinar, aprender e avaliar. As diversas caracterizações abrangeram desde ideias que denotam maior centralidade no professor e passividade do aluno (transmitir, adquirir, moldar...) até caracterizaçóes que envolvem interação e troca entre os sujeitos (interagir, questionar, compreender, tornar livre...).

O trabalho em pequenos grupos constituiu outra das atividades propostas nesse módulo: os alunos deviam escolher uma estratégia educativa, realizar busca de bibliografia, procurar um vídeo que exemplificasse a estratégia, para depois disponibilizar esse 
conjunto de materiais para a turma. As estratégias de ensino-aprendizagem analisadas pelos grupos compreenderam: aula expositiva dialogada, mapa conceitual, dramatização, estudo de caso e seminário. Os grupos desenvolveram um efetivo mergulho na literatura, evidenciando autonomia e motivação para a busca dos textos e vídeos, o que permitiu uma fecunda discussão no fórum sobre estratégias. Ali foram socializadas as produções grupais, com o objetivo de que toda a turma tivesse conhecimento das diversas estratégias - desde aquelas mais centradas no professor e nos aspectos cognitivos até as que possibilitam maior interação e desenvolvimento integral dos sujeitos.

O grupo mostrou significativa evolução, evidenciando apropriação e reflexão sobre os textos propostos para consulta bibliográfica. A análise das mensagens mostrou riqueza conceitual e avanços em relação às primeiras explanações. As citações de autores, como Paulo Freire, os comentários sobre a importância da reflexão dos participantes sobre a prática docente evidenciaram a relevância de assumir a docência como profissão e seu papel fundamental na construção de uma sociedade democrática.

Sobre as estratégias de ensino vivenciadas durante a graduação, a maioria dos pósgraduandos, tanto os formados antes das DCN como os egressos mais recentes reclamaram da predominância de aulas expositivas, com forte caráter transmissivo por parte dos docentes, consequente passividade dos alunos e fragmentação teórico-prática. Os cenários de ensino privilegiados corresponderam à sala de aula, ao laboratório e aos serviços de saúde:

\begin{abstract}
Na minha graduação, as salas de aula tinham 100 alunos. A estratégia de ensino era basicamente aula expositiva no modelo tradicional, algumas expositivas-dialogadas, seminários e grupos de discussão. Eram utilizados como materiais em aula o retroprojetor, textos e quadro negro. Além da sala de aula, utilizávamos os laboratórios para aula prática. O contato com a prática profissional ocorreu no último ano, periodo de estágios, onde conhecíamos os locais de atuação, os papéis e responsabilidades da profissão. Porém, considerando as Diretrizes Curriculares, no aspecto de interação entre as matérias, interdisciplinaridade e dimensões humanistas, na graduação não ocorreram. (Nutricionista)
\end{abstract}

A maioria dos pós-graduandos vivenciou estratégias de ensino-aprendizagem centradas no professor. Porém, sugeriram propostas a serem introduzidas nos cursos de graduação, tais como: diversificar as estratégias de ensino, com a utilização de fóruns de discussão e uso de TIC, dar maior ênfase ao desenvolvimento da competência de liderança e à articulação teoria-prática. Relatos de estratégias inovadoras e ampliação dos cenários e sua relevância no processo formativo também foram referidos: 
A maioria das aulas era expositiva, mas todas as disciplinas tinham seminários; a professora responsável pelas disciplinas de licenciatura promovia sempre discussões em sala de aula, $e$ o professor de fisiologia vegetal dividia a sala em grupos, fazia leitura dos textos e sempre promovia atividades de discussão entre os grupos. (Bióloga)

Durante a graduação considero como estratégia de aprendizagem inovadora a inserção do aluno no Programa Saúde da Família (PSF). Durante o internato, tínhamos o "Internato Rural", com duração aproximada de dois meses e 15 dias, em que nos mudávamos temporariamente para uma cidade no interior do Estado ou éramos integrados em uma UBS da periferia da capital. No local éramos inseridos dentro do PSF e realizávamos atendimento nas UBS, visitas domiciliares e participávamos dos programas de saúde pública. Considero que foi inovadora na época, na tentativa de trazer o médico e estudante para dentro do SUS e da realidade da saúde em nosso país, em que vive a maioria da população. (Médico)

Entendemos que a aprendizagem é um conceito complexo, de múltiplas interfaces, que se constitui na atividade do sujeito a partir da realidade concreta. A aprendizagem se dá a partir de uma situação real vivida pelo educando, como ponto de partida para promover um processo de compreensão, reflexão e crítica e para interferir e modificar a realidade. No processo educativo precisam ser enfatizados os valores humanísticos, éticos e políticos, inspiradores da sociedade democrática. $\mathrm{O}$ educando torna-se o centro do processo de ensino-aprendizagem, particularizando as estratégias que favoreçam uma inter-relação concreta entre teoria e prática, em um movimento dinâmico entre ação-reflexão-ação, que proporcione a (re)construção do conhecimento por meio do diálogo e da problematização.

No módulo de avaliação, o fórum de discussão mostrou que a maioria dos alunos vivenciou, na graduação, procedimentos de avaliação somativa, centrados na nota numérica como medida do conhecimento adquirido, relacionados à aprovação/reprovação do aluno, com escassas experiências de avaliação formativa:

Acabamos sempre com os mesmos métodos de avaliação. Acho que ainda será [necessário] por algum tempo promover mudanças nesse sentido. Alguns conceitos estão tão enraizados nas instituiçôes de ensino que será preciso muito empenho para formalizar mudanças. Avaliação deve ser contínua ao longo de um período, em minha opiniāo, da pré-escola à graduação. (Biomédica)

Embora a avaliação somativa tenha sido alvo de críticas, muitos alunos indicaram que ela é necessária como ferramenta para medir o armazenamento de 
conteúdos. Essas reflexões evidenciam uma concepção pedagógica tradicional, à qual Paulo Freire se refere como "educação bancária” (Freire, 1975, p. 70).

Os relatos evidenciaram poucas inovações nos procedimentos avaliativos nos cursos de graduação, embora tivessem citado: seminários, discussões, aulas práticas e relatórios. Porém, alguns alunos indicaram a necessidade de integração do processo de ensino-aprendizagem ao de avaliação. Esse posicionamento mostrou concordância com a perspectiva de Freitas e Seiffert (2007): a diversificação de estratégias e cenários aprimora a formação profissional na graduação, oferecendo benefícios para professor, aluno, população e para a saúde brasileira.

Reflexões sobre professores autoritários e resistentes a mudanças durante a graduação fizeram parte dos relatos dos estudantes:

Nos últimos anos da minha graduação, essa mudança curricular começou, e os professores também tentaram se opor às mudanças. (Fisioterapeuta)

Todos os conceitos da aprendizagem significativa me remeteram a experiências com professores que, muitas vezes, não consideram a bagagem cultural do aluno e que não gostam de ser questionados. Acham-se donos do saber, e os alunos devem fazer as tarefas recomendadas e absorver tudo que foi dito. Acredito que muitos já vivenciaram isso. (Bióloga)

Porém, alguns pós-graduandos relataram a importância de ter tido contato com alguns "poucos" professores que gostavam da docência.

Acho que a postura do professor formador está mudando, pois
o professor mostra-se mais autônomo e mais disponivel para es-
truturar as situaçôes de formação em situaçōes de aprendizagem,
privilegiando assim diferentes significados entre o aprendizado,
o ensino e a formação dos alunos, abrindo portas para um ensino
mais construtivo e atuante. (Nutricionista)

Essa polarização reflete bem a realidade de nossos espaços de formação, em que convivem diferentes modelos sobre os quais é preciso refletir para adequar os processos de ensino-aprendizagem à formação de cidadãos críticos, autônomos, comprometidos e participantes dos processos de transformação social.

Para aprender a aprender, a ser, a fazer, a viver juntos e a conhecer do ponto de vista da humanização do SUS, épreciso, em primeiro plano, professores com orientação humanista, preparo técnico e experiência no campo da saúde. (Psicóloga)

A formação do professor sinaliza para a organização curricular inovadora que, ao ultrapassar o modelo tradicional, estabelece novas relações entre teoria e prá- 
tica, oferece condiçôes para a emergência do trabalho coletivo e interdisciplinar e possibilita o desenvolvimento de competências técnicas e políticas que permitem ao educador e ao educando situar-se criticamente diante da realidade social.

O projeto de avaliação de tendências de mudanças no curso de Medicina, realizado por Perim e colaboradores (2009), ressalta a importância de adequar a formação profissional às demandas contemporâneas de saúde, mostra evidências de que a maioria das IES mantém um modelo pedagógico tradicional e de que, dentre os eixos avaliados, o de Desenvolvimento Docente é o que se encontra mais distante do preconizado nas atuais Diretrizes Curriculares Nacionais.

Nesse contexto, a formação docente na área da saúde exige especial importância no processo de reorganização curricular e do papel do professor no desenvolvimento pessoal e profissional:

Hoje, sou professora universitária e vejo que as coisas estão tendendo a mudanças. Na faculdade onde leciono, os alunos estão sendo instruidos desde o primeiro semestre sobre as politicas públicas, como SUS, PSF, saúde pública, questôes estas, que estão sendo bastante cobradas nas provas do MEC. A interdisciplinaridade ainda está engatinhando, mas, pelo menos, já estamos tentando passar do engatinhar para os primeiros passos. (Fisioterapeuta)

Conscientizei-me de que poderei ampliar meu papel no mundo, tentando, assim, propagar o que aprendi aqui. Lembrei também de uma paciente que me contou o motivo pelo qual ela escolheu ser professora... ela disse:

Minha vida e a do meu irmão já estavam fadadas a ser como a de outras pessoas que moram em minha cidade. Meu irmão terminou o colegial e tinha duas opções: ir para o Japão ou trabalhar na roça com o meu pai. Mas uma professora mudou nosso destino. Ela pediu para minha mãe nos dar uma outra oportunidade, incentivando-nos a fazer uma faculdade. Ele fez Direito e hoje é juiz. E, a partir deste momento, eu quis ser professora... foram apenas algumas palavras, mas isso mudou o rumo de nossas vidas. (Psicóloga)

O planejamento educacional, realizado de forma transversal durante todo o período da disciplina, evidenciou que os módulos de conteúdo específico subsidiaram esse processo de construção coletiva. A análise dos dez temas escolhidos pelos grupos para desenvolver esse planejamento permitiu-nos classificá-los em três áreas: 1. Prevenção e educação no âmbito comunitário; 2. Humanização no âmbito hospitalar; e 3. Aspectos anatomopatológicos de doenças prevalentes. Os 
planejamentos agrupados nas duas primeiras áreas refletiram uma visão próxima do modelo da integralidade, considerando a multideterminação do processo de saúde-doença e compreenderam a importância da diversidade de estratégias e cenários de ensino-aprendizagem com a comunidade. Já o terceiro mostrou uma visão reducionista, focada no modelo biomédico e privilegiando estratégias de ensino centradas no modelo transmissivo. Essa diversidade de modelos presente nos planejamentos é reflexo das diversas abordagens que convivem hoje nos cenários de ensino e assistência à saúde.

Na visão de Batista (2004, p. 51), as mudanças no ensino superior em saúde precisam avançar:

[...] do paradigma flexneriano ao do integralidade; do enfoque de doenças à ênfase na promoção da saúde; da transmissão da informação à construção de conhecimento; da compartimentalização disciplinar à integração, do hospitalocentrismo à diversidade dos cenários de ensino e aprendizagem, da centralidade no saber docente à escolha de conteúdos baseada nas necessidades sociais [...]

No trabalho com a disciplina, os pós-graduandos foram estimulados a desenvolver habilidades metarreflexivas sobre suas concepções e suas práticas durante o processo de aprendizagem:

Considero que esta foi uma das melhores partes do curso! Nunca tinha parado para pensar como havia sido minha formação durante a graduação e que novos modelos didático-pedagógicos eu poderia implantar no futuro. Relembrar o passado, agregando os novos conhecimentos sobre as diretrizes curriculares e os novos modelos didático-pedagógicos foi extremamente enriquecedor. A responsabilidade docente é muito grande, e temos que ter consciência de que seremos formadores de uma sociedade. (Farmacêutico)

Segundo Oliveira (2009), desenvolver competências metarreflexivas estimula a autonomia dos sujeitos, já que eles se apropriam do processo de construção de conhecimentos. Consideramos que essa competência adquire especial importância numa trajetória de formação docente que considere a complexidade do atual contexto de mudanças e que se proponha a articular as dimensões pessoais, institucionais, políticas e sociais para contribuir para o aprimoramento da formação de profissionais. 


\section{Considerações finais}

No atual momento de mudança, o Sistema Educacional Brasileiro, que avança em consonância com o processo de implantação e expansão de Políticas de Saúde, em especial com o SUS, demanda a adequação dos processos de formação docente na área da saúde. Nessa direção, é relevante a consolidação de espaços de formação que favoreçam futuras aprendizagens e o enfrentamento de problemas e desafios no âmbito do exercício profissional. A concretização desse desafio exige tomar como foco de reflexão e problematização o trabalho docente, com a perspectiva de qualificar a formação profissional de nível superior (Freitas; Seiffert, 2007).

Lopes Neto e colaboradores (2007) revelaram que o índice de aderência de cursos da área da saúde às DCN é considerado abaixo das expectativas. Apesar do tempo decorrido, era esperada uma maior identificação dos cursos com os postulados preconizados por essas diretrizes. A transformação do perfil dos futuros profissionais da saúde deveria efetivar-se pela adoção de estratégias dirigidas ao campo da formação dos profissionais, construídas com base nos princípios do sistema público de saúde, além de fundamentadas no conceito ampliado de saúde; pela utilização de metodologias ativas de ensino-aprendizagem, que considerem o trabalho em saúde como eixo estruturante das atividades; pelo trabalho multiprofissional e transdisciplinar; pela integração entre o ensino e os serviços de saúde; pelo aperfeiçoamento da atenção integral à saúde da população.

As concepções e as práticas dos pós-graduandos, participantes da disciplina Formação Didático-Pedagógica em Saúde na proposta bimodal, apreendidas neste trabalho, refletem o momento de transição do Ensino Superior brasileiro, em que convivem abordagens baseadas no modelo biomédico e na pedagogia tradicional, com inovações ainda incipientes sobre as quais é preciso debater de forma reflexiva e crítica. Consolidar e ampliar espaços de formação docente que valorizem a experiência prévia dos participantes, as reflexôes sobre a prática profissional e a proposta de ações inovadoras mostram-se como aspectos cruciais diante das atuais demandas. Estimular processos metarreflexivos sobre a própria aprendizagem parece potencializar o desenvolvimento de competências para a atuação docente comprometida com processos de transformação. A construção deste trabalho implicou na identificação de aspectos que consideramos essenciais nos processos de formação docente da Saúde que se concretizam na Unifesp. A formação docente não é tarefa fácil nem imediata. Entretanto, as experiências da Unifesp evidenciam possibilidades de consolidar trajetórias diferentes por meio do entendimento da docência universitária e das práticas didáticas inerentes à formação do profissional nas Ciências da Saúde, acorde com as atuais demandas sociais e ambientais do País. 


\section{Referências bibliográficas}

BATISTA, N. A. Planejamento na prática docente em saúde. In: BATISTA, N. A.; BATISTA, S. H. S. (Org.). Docência em saúde: temas e experiências. São Paulo: Senac, 2004.

BATISTA, N. A. et al. A disciplina "Formação Didático-Pedagógica em Saúde" na PósGraduação Stricto Sensu da Unifesp/EPM: uma proposta em foco. In: BATISTA, N. A.; BATISTA, S. H. S. (Org.). Docência em saúde: temas e experiências. São Paulo: Senac, 2004.

BRASIL. Ministério da Educação. Conselho Nacional de Educação. Câmara de Educação Superior. Diretrizes Curriculares para os cursos da Saúde, 2000-2002. Disponível em: $<$ http://portal.mec.gov.br/index.php?option=com_content\&view=article\&id=12991: diretrizes-curriculares-cursos-de-graduacao- $\&$ catid=323:orgaos-vinculados $>$. Acesso em: jul. 2011.

CENTRO DE DESENVOLVIMENTO DO ENSINO SUPERIOR EM SAÚDE. Relatório 10 anos. São Paulo: Cedess/Unifesp. Disponível em <http://www.unifesp.br/ centros/cedess, 2006>. Acesso em: jul. 2010.

FREIRE, Paulo. Pedagogia do oprimido. 2. ed. Rio de Janeiro: Paz e Terra, 1975.

FREIRE, Paulo. Extensão ou comunicação? 4. ed. Rio de Janeiro: Paz e Terra, 1979.

FREITAS, M. A.; SEIFFERT, O. M. L. B. Formação docente e o ensino de pós-graduação em saúde: uma experiência na Unifesp. Revista Brasileira de Enfermagem, Brasília, v. 60, n. 6, p. 635-640, 2007.

LOPES NETO, D. et al. Aderência dos cursos de graduação em enfermagem às diretrizes curriculares nacionais. Revista Brasileira de Enfermagem, Brasília, v. 60, n.6, 2007. Disponível em <http://www.scielo.br/scielo.php?>. Acesso em: mar. 2011.

MAIA, J. A. O currículo no ensino superior em saúde. In: BATISTA, N. A.; BATISTA, S. H. (Org.). Docência em saúde: temas e experiências. São Paulo: Senac, 2004.

MASETTO, M. T. Competência pedagógica do professor universitário. São Paulo: Summus, 2003.

NUNES, C. M. F. Saberes docentes e formação de professores: um breve panorama da pesquisa brasileira. Revista Educação e Sociedade, Campinas-SP, v. 22, n. 74, p. 27-42, 2001.

OLIVEIRA, M. K. Cultura e psicologia: questões sobre o desenvolvimento do adulto. São Paulo: Hucitec, 2009.

PERES, A. M.; CIAMPONE, M. H. T.; WOLFF, L. D. G. Competências gerenciais do enfermeiro nas perspectivas de um curso de graduação de enfermagem e do mercado de trabalho. Revista Trabalho Educação e Saúde, Rio de Janeiro, v. 5, n. 3, p. 45-47, 2007. Disponível em: <http://www.epsjv.fiocruz.br/beb/periodicos/mfn9055>. Acesso em: mar. 2011. 
PERIM, G. L. et al. Desenvolvimento docente e formação de médicos. Revista Brasileira de Educação Médica, Rio de Janeiro, v. 33, n. 1, p. 70-82, 2009. Suplemento 1.

RUIZ-MORENO, L. et al. Formação didático-pedagógica em saúde: avaliação da proposta bimodal no ambiente Moodle, 2010. Mimeo.

RUIZ-MORENO, L.; PITAMIGLIO, S. E. L.; FURUSATO, M. A. Lista de discussão como estratégia de ensino-aprendizagem na pós-graduação em Saúde. Interface, Botucatu, v.12, n. 27, p. 883-892, 2008. On-line. Disponível em: http://www.scielo.br/scielo. php?pid=S1414-2832008000400017\&script=sci_arttext Acesso em: fev. 2011.

RYAN, J.; SCOTT, A. Integrating technology into teacher education: how online discussion can be used to developed informed and critical literacy teachers. Teaching and Teacher Education, Standford, v. 24, n. 6, p. 1635-1644, 2008.

SEIFFERT, O. M. L. B. Unifesp: de uma escola livre de medicina a universidade da saúde. In: MOROSINI, M. (Org.). A universidade no Brasil: concepções e modelos. Brasília: Ministério da Educação/ INEP, 2006.

VYGOTSKY, L. A formação social da mente. São Paulo: Martins Fontes, 1998.

Recebido em 09 de setembro de 2010 e aprovado em 31 de março de 2011. 